\title{
Minerals in Our Environment
}
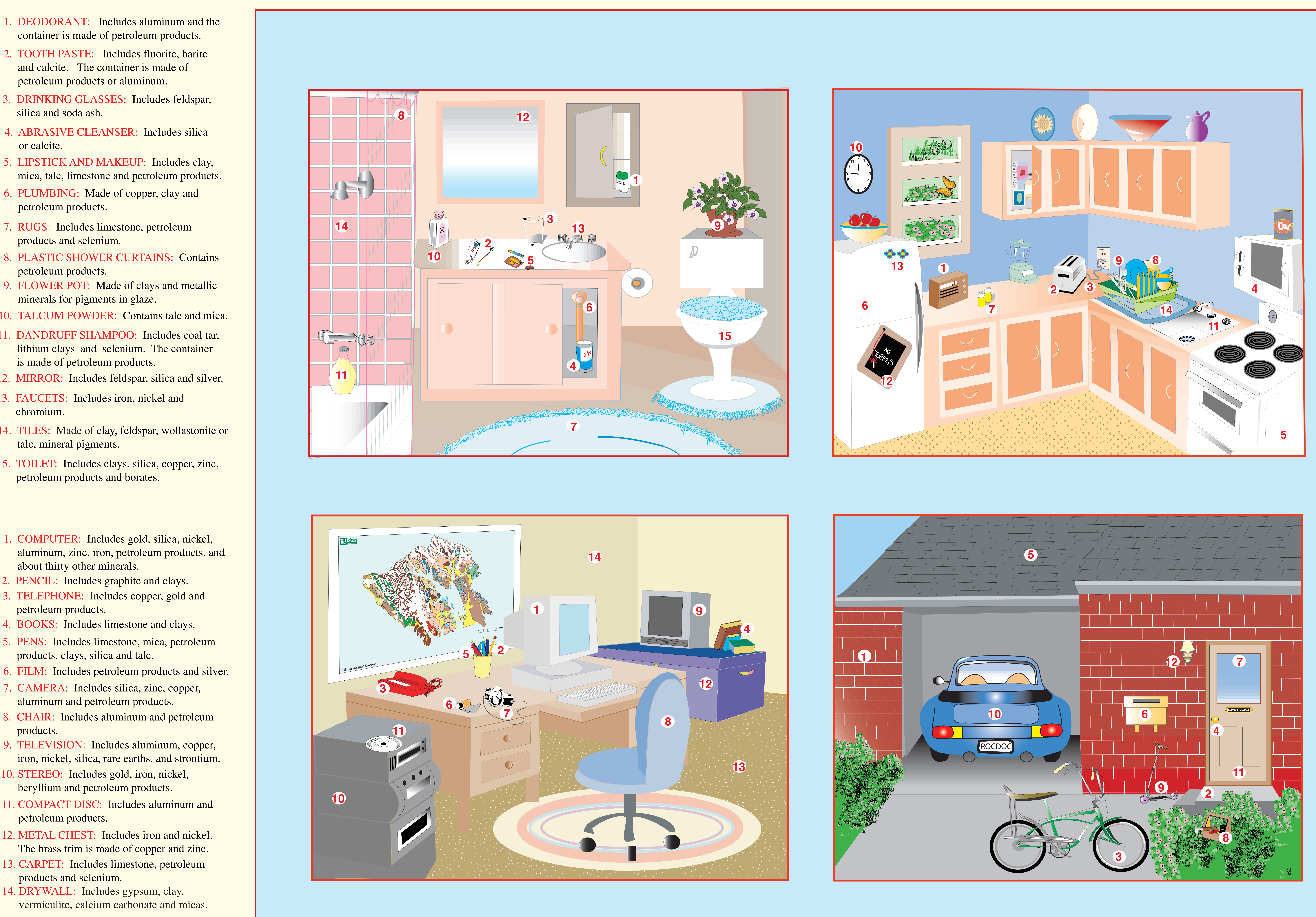

RADIO: Includes aluminum, copper, gold, TOASTER: Includes copper, iron, nickel,
mica, chromium and perolum products. ELECTRICAL WIRRING: Includes copper
aluminum and perofoleun products aluminum and petroleum products.
4. MICRO WAVE: Includes copper, gold, iron,
nickel and silica

nickel and silica.
STrove: Includes aluminum, copper, iron,
nickel and silicas REFRIGERATOR: Includes aluminum,
copper, iron, nickel, petroleum products
and zinc.

TABLE SALT: Includes halit; light salt can
be made from sylvite. Most salt has added iodine.
8. PLATES: Includes clays, silica and feldspar 9. CUTLERY: Includes iron, nickel, silver and chromium.
0. CLOCK: Includes iron, nickel, petroleum STAINLESS STEEL SINK: Includes iron and nickel.
BLACKBDARD: Includes clays, Chalk
includes imestone or pertolueum products. includes limestone or petroleum products
in 13. MAGNET: Includes cobalt.
DISH RACK: Made of petroleum products
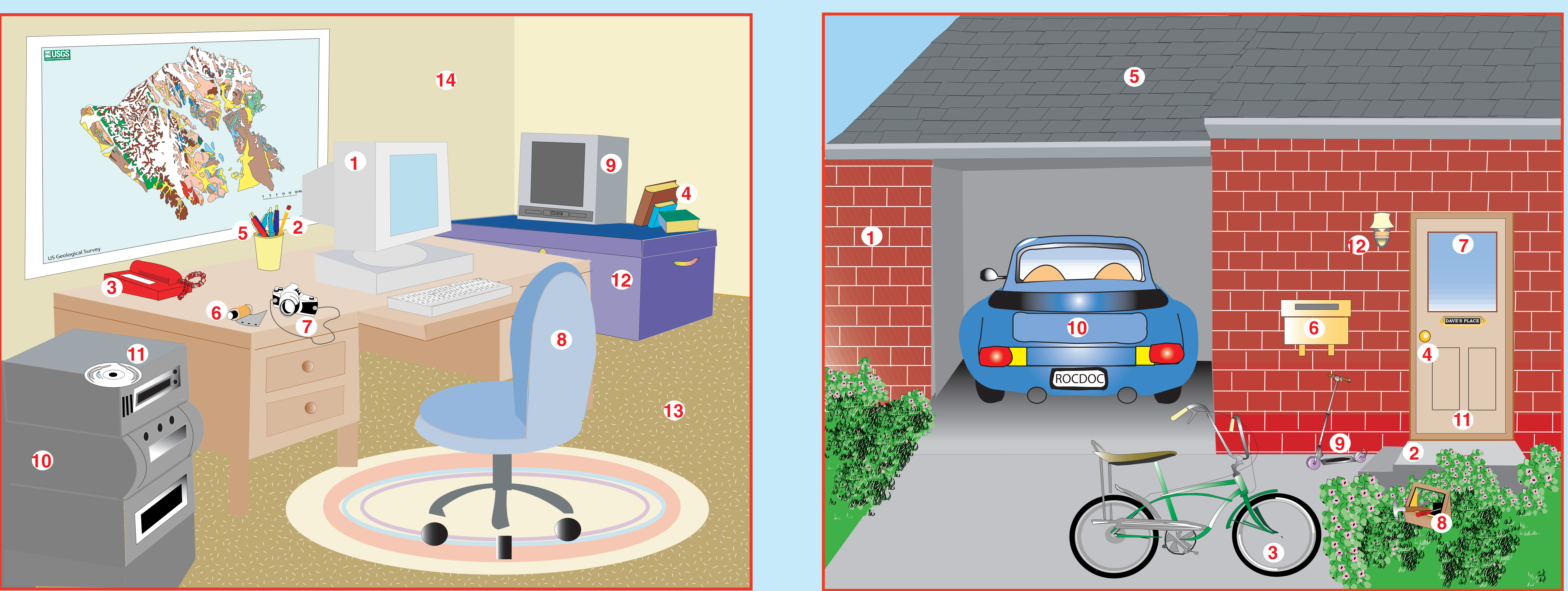

BRICKS: Includes graphite, clays and silicen

iron, limestone, clays and silica.

BIKE: Includes barite, iron, nickel and
petroleum products

DOOR KNOB: Includes copper and zinc, which

SHINGLES: Includes petroleum products and clays

. MAll BOX: Includes copper and zinc, which
make brass.

WINDOWS:

TOOLS: Includes iron and nickel.

SCOOTER: IIcludes aluminum, calcite, mica,
nickel, pertoleum droducts,s clayy, silica and talc.

AUTOMOBILE: Includes aluminum, barite, calcite.
iron, lead, mica, nickel, pertroleum products, clays,

sulfur: Includes titanium, gypsum, barite and
2. LGHTT AND FXXUREE: Includes tungsten, 